\title{
VALIDACION DE DOS OFICIOS Y LEVANTAMIENTO DE DOS OFICIOS DE RR.HH REQUERIDOS POR EL SECTOR TURISMO DE LA REGION DE LOS LAGOS.
}

\section{ANTECEDENTES}

La Región de Los Lagos se caracteriza por tener una gran extensión geográfica ( $10 \%$ del territorio nacional), grandes atractivos turísticos que la hacen una de las más promisorias en términos de posibilidad de incremento de esta actividad en esta zona. Esto sustenta el irrefutable dato de un incremento constante de afluencia de visitantes a la región, que se ha vuelto una constante en los últimos diez años. Cada una de las cinco zonas turísticas, poseen atractivos propios, otorgando una diversidad de posibilidades turísticas, lo cual permite afirmar que potencialmente puede satisfacer la gama más diversa de intereses del turista. En consonancia, el gobierno regional ha expresado en sus prioridades para el desarrollo y educación del recurso humano "el desarrollo de áreas con potencial productivo en función de sus recursos naturales es de suma importancia, lo que sumado a la incorporación de nueva tecnología y procesos productivos limpios, dinamizan la economía regional, diversificando y modernizando los rubros productivos tradicionales, haciéndolos más competitivos, considerando al turismo como eje orientador para las demás actividades económicas de la Región "

Sin embargo, en el curso de la investigación se pudo constatar que existe un desarrollo precario de productos turísticos, pudiendo convocar en forma más masiva y/o selectiva a turistas que buscan cada vez más, un servicio integral y profesional, que no sólo proporcione servicios turísticos tradicionales, sino también otras formas de esparcimiento como el etnoturismo, el turismo aventura, ecoturismo y el turismo cultural.

La transformación de la Región de Los Lagos en un destino preferente a nivel internacional, requiere un gran esfuerzo que compromete al país y a la región en su conjunto, para desarrollar un turismo sustentable, de mínimo impacto ambiental. Se debe también considerar el fomento a iniciativas locales y comunitarias que puedan aprovechar su patrimonio cultural y natural. Por otro lado, se constata la existencia de muy escasas normas que cautelen la seguridad de los turistas en 
áreas emergentes como el turismo aventura, tema a considerar para poder competir en los mercados internacionales.

El desarrollo de los recursos humanos, ligados a esta actividad y los requerimientos que se plantean al sector son notables, por un lado la capacidad de atender a los turistas en general y extranjeros en particular, es decir, además de todos los esfuerzos de una estrategia de marketing, se necesita la incorporación de conocimientos de un idioma extranjero (inglés), lo que aparece como un déficit en el sector.

\section{OBJETIVOS}

\subsection{Objetivos Generales}

- Comprobar si las competencias establecidas en los oficios de garzón y barman levantados por la Fundación Chile, tienen aplicabilidad o necesitan otras competencias en la décima región.

- Levantar las competencias de dos nuevos oficios emergentes en el sector turismo, de acuerdo a la región de Los Lagos.

\subsection{Objetivos Específicos}

- Determinar las brechas concretas y/o competencias adicionales existentes entre el perfil de los oficios de Garzón y Barman, levantados por Fundación Chile y las reales demandas del sector productivo de la Décima Región.

- Levantar el perfil profesional y el campo laboral de dos oficios de acuerdo a metodologías pertinentes a la realidad del sector y a la fecha de realización del estudio.

- Determinar la demanda de recursos humanos y la localización de ésta para cada uno de los nuevos oficios levantados.

\section{METODOLOGIA}

Se optó por dos metodologías: 1) "Cuestionario de Análisis Ocupacional", correspondiente a la temporada alta de turismo (enero, febrero 2005) y 2) Metodología DACUM. 
La Metodología DACUM, idealmente necesita que los especialistas estén reunidos a lo menos un día para el logro eficiente de los objetivos.

El Cuestionario de Análisis Ocupacional, es una metodología de análisis ocupacional, apropiado para elaborar perfiles ocupacionales. Son entrevistas personales, con preguntas estructuradas y semiestructuradas.

\section{ANÁLISIS DE LOS RESULTADOS}

\subsection{Primera Parte:}

\section{Validación de los oficios de barman y garzón}

\section{A.- Sobre los ejecutivos}

Las dificultades en el desempeño laboral que los directivos de las empresas expresan, en relación con el conjunto de sus trabajadores son:

- Falta de manejo de idiomas (principalmente inglés), para atender a clientes extranjeros.

- Falta de habilidades en el manejo de las relaciones interpersonales entre trabajador y cliente.

- Falta de respeto a las normas que dicen relación con ausentismo y presentación personal.

- Falta de motivación y compromiso con el trabajo.

Con respecto a conductas a mejorar en los trabajadores para un buen desempeño, se expresa que los trabajadores deben tener: motivación, creatividad, iniciativa, proactividad, y actitud con disposición a los cambios. También se manifiesta que los trabajadores deben ser más asertivos frente a situaciones imprevistas y que además manejen un buen vocabulario en la atención de los clientes. Cabe señalar que deben mejorar el trato hacía el cliente, reconociendo esto como la prioridad número uno del rubro. Aparece también la disposición al trabajo en equipo, la responsabilidad en horarios y normas.

Las dificultades específicas del desempeño en cada oficio (barman y garzón) son:

Garzón: el principal problema es el idioma y el trato con los clientes.

Barman: el manejo del idioma inglés, falta de creatividad y proactividad. 
Por lo tanto, el problema del idioma aparece como el más relevante en relación a los dos oficios estudiados y para el conjunto de los trabajadores del rubro.

\section{B.- Sobre los garzones}

De la aplicación del instrumento, se concluye que las actividades claves y los criterios establecidos por la Fundación Chile han sido validados en su mayoría, puesto que están presentes mayoritariamente en los análisis.

Llama la atención la diferencia entre el desempeño de tareas en empresas grandes y pequeñas. En general, en las grandes empresas, las tareas asignadas al garzón, son más específicas y están orientadas al servicio directo del cliente. Por el contrario, en las empresas pequeñas, los garzones tienden a ejecutar todas las tareas, incluidas las de aseo, ejerciendo dos oficios.

Con respecto a las capacitaciones que han recibido, destacan las de atención al cliente, bar y coctelería, barman, cocina, manipulación de alimentos, inglés, ventas, cata de vino, técnicas culinarias y preparación de mesas.

\section{C.- Sobre el barman}

Se hizo una caracterización global de todo el barman entrevistado, de lo cual se concluye:

- La mayoría tiene una escolaridad igual o superior a enseñanza media completa

- Al igual que los garzones, la incorporación a este oficio se produce a una edad muy temprana.

Con respecto a las capacitaciones que han tenido, las más significativas son bar y coctelería, barman, atención al cliente y cata de vino. 


\subsection{Segunda Parte: \\ Necesidades de Oficios de Turismo y nuevos perfiles ocupacionales de dos oficios de turismo en la Región de Los Lagos.}

\section{A.- Definición de los Oficios nuevos}

Los ejecutivos de empresas gastronómicas y hotelera, establecieron que la necesidad de Guías turísticos es la más relevante. Por otro lado, los informantes claves coincidieron en forma unánime sobre la necesidad de desarrollar el oficio de guía turístico en la región y enfocaron el concepto de Guía turístico desde dos dimensiones:

- Dimensión de la cultura y la recreación

- Dimensión de la aventura y del ecoturismo

Por consiguiente, la propuesta optó por el Guía Turístico Cultural y el Guía de Turismo Aventura y Ecoturismo.

\section{B.- Estructura del perfil ocupacional de estos oficios}

La información recogida, se concluye que son tres las grandes unidades de competencia para los perfiles ocupacionales de los dos oficios son:

- Organizar actividades turísticas

- Guiar a los turistas

- Liderar a grupos de turistas

Las unidades de competencia Organizar actividades turísticas y liderar a grupos de turista, no tienen grandes diferencias en sus actividades claves y criterios de desempeño, siendo ellas válidas para los dos oficios, con las adecuaciones mínimas correspondientes, por ejemplo, en términos de conocimientos relevantes previos para la organización de las actividades.

Sin embargo, los oficios se diferencian fuertemente en la unidad de competencia Guiar a los turistas, estas diferencias se reflejan en requerimientos distintos desde el punto de vista dej conocimiento y las características personales. 


\section{C.- Diferencias entre el guía de turismo aventura y ecoturismo y el guía de turismo cultural}

Estos deben tener competencias distintas, de aquí se deducen motivaciones, conocimientos y características personales y conocimientos que debe poseer.

Para el turismo aventura, las exigencias son mayormente de tipo físico, control de situaciones extremas y de gusto por la aventura. Por otro lado el guía de turismo cultural, propende mayormente a exigencias que tienen que ver con intereses por conocimientos históricos y sociales, siendo las exigencias físicas de un rango más moderado, pero necesario por el desempeño en terreno. Por lo tanto las principales características y conocimientos que deben tener cada uno de ello, se resume en el siguiente cuadro:

\section{Características, conocimiento y habilidades por oficio.}

\begin{tabular}{|c|l|}
\hline \multicolumn{2}{|c|}{ Características Personales } \\
\hline $\begin{array}{c}\text { Guía de } \\
\text { Turismo } \\
\text { Aventura y } \\
\text { Ecoturismo }\end{array}$ & $\begin{array}{l}\text { Paciencia, atención al cliente, condición física, motivación, disposición, espíritu } \\
\text { aventurero, liderazgo, buena presencia, respeto por la naturaleza, } \\
\text { responsabilidad, prevenir acciones inseguras, cordialidad }\end{array}$ \\
\hline $\begin{array}{l}\text { Guía de } \\
\text { Turismo } \\
\text { Cultural }\end{array}$ & Personalidad, empatía, manejo de grupo, liderazgo y motivación \\
\hline \multicolumn{2}{|c|}{ Conocimientos y Habilidades } \\
\hline $\begin{array}{c}\text { Guía de } \\
\text { Turismo }\end{array}$ & Idioma, cultural general, flora y fauna, primeros auxilios, geografía, climatología \\
Aventura y & hora nacional, rescate, manejo de grupos, cartografía, manejo de medio ambiente, \\
Ecoturismo & prevención de riesgos. \\
\hline $\begin{array}{l}\text { Guía de } \\
\text { Turismo } \\
\text { Cultural }\end{array}$ & $\begin{array}{l}\text { Idioma, historia, geografía, antecedentes regionales, cultura general, flora y fauna, } \\
\text { primeros auxilios. }\end{array}$ \\
\hline
\end{tabular}


D.- Análisis de la información obtenida a través de los juicios de expertos de Perfiles de Guía de Turismo Aventura y Ecoturismo y Guía de Turismo cultural.

\section{D.1. Perfil Ocupacional:}

\section{Guía de Turismo Aventura y Ecoturismo}

Este oficio es bastante nuevo, existiendo una alta presencia de guías extranjeros con dominio de otros idiomas, especialmente el inglés, los que han hecho cursos u obtenido certificaciones en esos países y se han avecindado en el país con un éxito creciente.

\section{Unidad de Competencia: Organizar Actividades Turísticas}

- Actividad clave: Crear circuitos o actividades de turismo aventura.

\section{Unidad de Competencia: Guiar a los turistas}

- Actividad clave 1: Recibir e informar a los clientes

- Actividad clave 2: Organizar, enseñar a remar y guiar excursiones de kayak por río o por mar y rafting por río.

- Actividad clave 3: Organizar, preparar y guiar excursiones para escalar montañas.

- Actividad clave 4: Organizar y dirigir canopy

- Actividad clave 5: Organizar y dirigir cabalgatas en sectores rurales

- Actividad clave 6: Organizar y dirigir turismo rural y étnico

- Actividad clave 7: Guiar turistas a pescar en embarcación u orilla

\section{Unidad de Competencia: Liderar grupos de turistas}

- Actividad clave 1: Animar actividades de recreación y entretención

- Actividad clave 2: Preparar campamento, carpas y registrar las excursiones

- Actividad clave 3: Asistir a pasajeros en caso de emergencia

- Actividad clave 4: Manejar crisis de grupos en actividades de turismo aventura

- Actividad clave 5: Asistir a pasajeros en caso de búsqueda o pérdida de objetos 


\section{D.2 Perfil Ocupacional: Guía de Turismo Cultural}

\section{Unidad de Competencia: Organizar actividades de turismo cultural}

Actividad clave 1: Crear circuitos o actividades de turismo rural

\section{Unidad de Competencia: Guiar a los turistas}

- Actividad clave 1: Recibir e informar a los clientes

- Actividad clave 2: Guiar actividades de interés histórico y científico

- Actividad clave 3: Guiar actividades turístico recreativo

- Actividad clave 4: Organizar y dirigir caminatas con fines recreativos o culturales

\section{Unidad de Competencia: Liderar grupos de turistas}

- Actividad clave 1: Animar actividades de recreación y entretención

- Actividad clave 2: Preparar campamentos, comidas y registrar las excursiones

- Actividad clave 3: Asistir a pasajeros en caso de emergencia

- Actividad clave 4: Manejar crisis de grupos en actividades de turismo cultural

- Actividad clave 5: Asistir a pasajeros en caso de búsqueda o pérdida de objetos 